\title{
Time dependence of snow microstructure and associated effective thermal conductivity
}

\author{
P.K. SATYAWALI, ${ }^{1}$ A.K. SINGH, ${ }^{2}$ S.K. DEWALI, ${ }^{1}$ Praveen KUMAR, ${ }^{1}$ Vinod KUMAR ${ }^{1}$ \\ ${ }^{1}$ Snow and Avalanche Study Establishment (SASE), Manali, Himachal Pradesh 175103, India \\ E-mail: pramodsatyawali@hotmail.com \\ ${ }^{2}$ Defence Institute of Advanced Technology, Deemed University, Girinagar, Pune 411025, India
}

\begin{abstract}
This paper presents a sequential evaluation of snow microstructure and its associated thermal conductivity under the influence of a temperature gradient. Temperature gradients from 28 to $45 \mathrm{~K} \mathrm{~m}^{-1}$ were applied to snow samples having a density range $180-320 \mathrm{~kg} \mathrm{~m}^{-3}$. The experiments were conducted inside a cold room in a specially designed heat-flux apparatus for a period of 4 weeks. A constant heat flux was applied at the base of the heat-flux apparatus to produce a temperature gradient in the snow sample. A steady-state approach was used to estimate the effective thermal conductivity of snow. Horizontal and vertical thick sections were prepared on a weekly basis to obtain snow micrographs. These micrographs were used to obtain snow microstructure using stereological tools. The thermal conductivity was found to increase with increase in grain size, bond size and grain and pore intercept lengths, suggesting a possible correlation of thermal conductivity with snow microstructure. Thermal conductivity increased even though surface area and area fraction of ice were found to decrease. The outcome suggests that changes in snow microstructure have significant control on thermal conductivity even at a constant density.
\end{abstract}

\section{INTRODUCTION}

In a seasonal snowpack, the possible mechanisms whereby energy can be transported from one region of space to another under the influence of a temperature gradient are: radiation, convection, water-vapour diffusion and thermal conduction (Yosida and others, 1955; Akitaya, 1974). In most practical situations, all these processes to some extent accomplish energy transport, but the relative importance of each contribution can vary markedly. For example, on the surface of a solid material, radiation, conduction and convection are the sole mechanism of heat transport; whereas, inside the body, conduction is the only mechanism possible. Many important materials are of uniform composition throughout, and for them the thermal conductivity is a true physical property of the material, often depending only on the temperature, pressure and composition of the sample. However, in the case of snow, while radiation is the dominant mechanism of heat transfer at the surface, conduction and diffusion also contribute to heat transfer. Therefore, the thermal conductivity is not strictly a property of snow, since it can depend on a large number of parameters, including the history of the material, its development over time and internal structure (Brun and others, 1992; Adams and Sato, 1993; Arons and others, 1994; Arons and Colbeck, 1995; Sato and Adams, 1995; Sturm and others, 1997; Lehning and others, 2002; Schneebeli and Sokratov, 2004; Kaempfer and others, 2005). For this reason, the thermal conductivity is referred to as the effective thermal conductivity (ETC). ETC has been found to vary considerably (Yen, 1962, 1965, 1981; Sturm, 1991; Sturm and Johnson, 1992; Sturm and others, 1997), depending mostly on the snow structure (Schneebeli and Sokratov, 2004). Therefore, the ETC of materials like snow, sand and soil is taken to be the empirical constant of proportionality in the linear relationship between the measured heat transport per unit area and the temperature difference over a prescribed distance in the material. However, this distinction between homogeneous and inhomogeneous materials is often ignored, leading to confusion, especially where intercomparisons among measurements are concerned (Sturm and others, 1997).

In most practical situations, where all three heat-transfer mechanisms are present, the process of measuring the thermal conductivity is greatly complicated. Thus, simple measurements made in the field are inadequate, and it has been difficult to devise measurement methods that unequivocally determine thermal conductivity as a function of controlling processes (Wakeham and Assael, 1999).

Many researchers have modelled the thermal conductivity of snow based on its microstructure (Adams and Sato, 1993; Arons and Colbeck, 1998), but these models require fine details about snow before they can be implemented practically. These models were applied to simulate the heat transfer within the snowpack (Brun and others, 1992; Bartelt and Lehning, 2002) with limited success. Recently, Schneebeli and Sokratov (2004) have conducted experiments in a small test device using X-ray computed tomography. The non-destructive experiments were run for 8-12 days under a temperature gradient. Interestingly, they found a slight decrease in ETC in the initial period of metamorphism for fresh snow, followed by an increase. They also measured the structural changes of the snow along with the change in ETC with time. The results varied significantly for low- and highdensity snow. These experiments were untypical, as both ETC and the development of structural changes in snow were measured together.

In the present work, experiments were conducted in a specially designed heat-flux apparatus which provided a constant heat flux to the snow samples. ETC of snow was estimated after steady-state temperatures were achieved in the snow samples. A snow block was cut weekly to obtain snow micrographs and determine snow density. Various microstructural parameters were estimated, using the work of Edens (1997), and compared with the evolution of ETC. 
Table 1. Estimation of maximum heat leakage from the heat-flux apparatus for a test sample

\begin{tabular}{|c|c|c|c|c|c|}
\hline ETC of test sample & $\begin{array}{l}\text { Measured heat } \\
\text { flux at bottom of } \\
\text { test sample, } A\end{array}$ & $\begin{array}{c}\text { Measured heat } \\
\text { flux at } 10 \mathrm{~cm} \text { height of } \\
\text { test sample, } B\end{array}$ & $\begin{array}{c}\text { Average heat losses } \\
\text { through side-walls, } \\
\qquad[(A-B) \times 100] / A\end{array}$ & $\begin{array}{c}\text { Average estimated } \\
\text { heat losses in } \\
\text { sample } 4^{*}\end{array}$ & $\begin{array}{c}\text { Average estimated } \\
\text { heat losses in } \\
\text { sample } 6^{*}\end{array}$ \\
\hline $0.09 \mathrm{~W} \mathrm{~m}^{-1} \mathrm{~K}^{-1}$ & $5.64 \mathrm{~W} \mathrm{~m}^{-2}$ & $4.18 \mathrm{~W} \mathrm{~m}^{-2}$ & $25.9 \%$ & $20.2 \mathrm{~W} \mathrm{~m}^{-2}$ & $16.5 \mathrm{~W} \mathrm{~m}^{-2}$ \\
\hline
\end{tabular}

*Using conductivity value of Styrofoam as $0.033 \mathrm{~W} \mathrm{~m}^{-1} \mathrm{~K}^{-1}$ and an average temperature difference of $2.75^{\circ} \mathrm{C}$ between inner and the outer walls of foam.

\section{METHODS}

\subsection{Thermal conductivity}

Fourier's empirical law simply states that the heat $Q$ transported by conduction per unit area in a particular direction is proportional to the difference of the temperature, $\Delta T$, per unit length in that direction and is given by:

$$
Q=-k_{\mathrm{e}} \Delta T \text {. }
$$

The coefficient of proportionality is known as the ETC and denoted by symbol $k_{\mathrm{e}}$. To maintain a one-dimensional (1-D) heat flow and to minimize radial heat flow in the sample, the snow sample size is taken to be relatively larger than the area over which measurements are made. In practice, it is impossible to arrange an exactly $1-D$ heat flow in any finite sample, so there will always be a departure from the ideal situation (Wakeham and Assael, 1999).

The steady-state method used to measure the ETC of snow often employs the geometry of parallel plates. The heat-flux apparatus designed for the present work is shown in Figure 1a. The snow sample of height $d$ is placed over the base (copper) plate. A small amount of heat $(Q)$ is generated electrically at the base plate having an area $A$, and the heat $(Q)$ is transported through the sample to the snow surface. The temperatures of the snow surface and hot (copper) plate are measured very precisely, as is the electric input of energy, so that the ETC can, in principle, be evaluated from:

$$
Q=A k_{\mathrm{e}} \frac{\Delta T}{d} .
$$

The electric energy generated at the hot plate is assumed to be conducted through the snow surface. Although the insulation around the snow sample was enough, it was difficult to prevent spurious heat losses. However, to ensure 1-D heat flow, a larger snow sample size was taken in our experiments. Temperature was measured at different depths of the snow sample in the horizontal plane (see section 2.2), ensuring that most of the heat from the hot plate went into the snow sample.

\subsection{Design of experimental apparatus}

A heat-flux apparatus having d.c. heaters at the base was designed with a view to conducting the temperature gradient experiments under controlled conditions. For this purpose, a high-resistance heater wire was evenly distributed over the entire base area to prevent any temperature variation. The heater was mounted on top of wooden blocks with a Bakelite base and insulation so that the bottom was insulated and all heat was trapped inside. The total wattage of the base heater was kept at $50 \mathrm{~W}$ for an area of $1.0 \times 0.3 \mathrm{~m}^{2}$ powered with a $12-24 \mathrm{~V}$ d.c. source. A plate of electrolytic grade copper with a base area of $1.0 \times 0.3 \mathrm{~m}^{2}$ and thickness of $6 \mathrm{~mm}$ (to sustain the weight of the snow sample) was kept above the heater, with a small air gap between the heater and copper plate, which helped in the heat transfer to the copper plate by radiation and convection. This achieved a slow and uniform rise in temperature and prevented the formation of hot spots on the copper plate. Six RTD-type temperature sensors (PT-100) were flushed within the copper plate to monitor its temperature. A schematic of the experimental set-up is shown in Figure $1 \mathrm{~b}$.

Before the experiments started, a uniform temperature distribution over the entire copper plate was ensured. The temperature of the copper plate was found to be within $0.55^{\circ} \mathrm{C}$ of the mean. Sufficient insulation $(100 \mathrm{~mm}$ Styrofoam) was provided at the bottom and sideways to reduce heat losses, and 1-D heat flow was maintained. In our case, $3 \%$ of the total heat generated by the heater escaped downwards from the bottom of the apparatus. This was determined by finding the difference between the amount of heat produced by the heater and the heat input to snow. To measure the heat losses from the side-walls, two heat-flux sensors were placed at the base plate, and two exactly above

Table 2. Experimental details of all the tests conducted on various snow samples in cold room

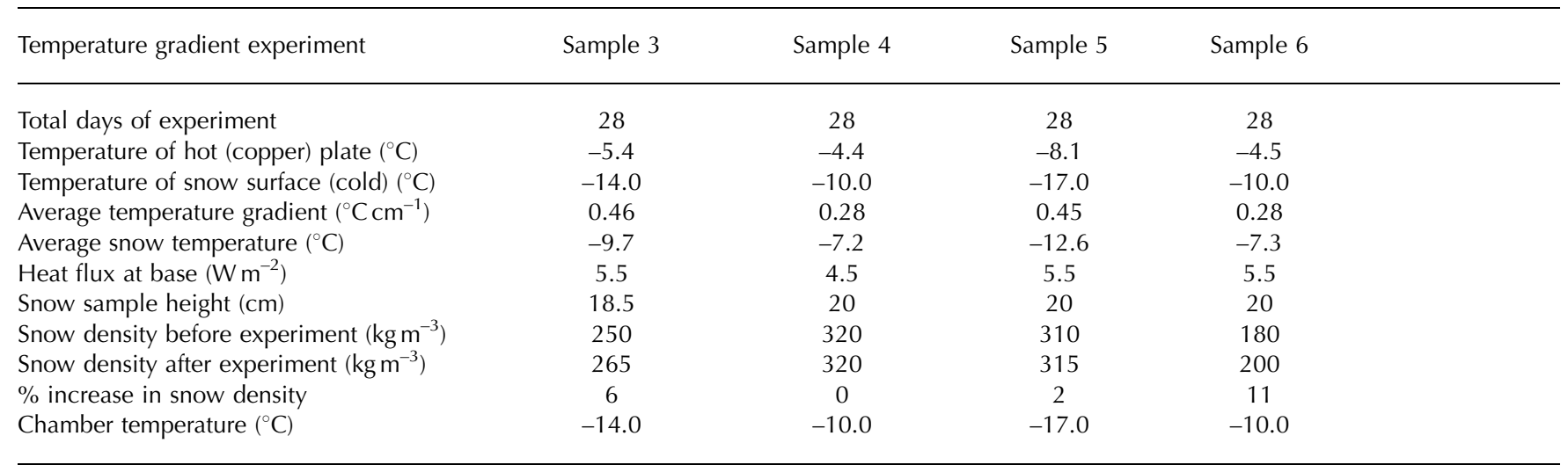


these sensors at a height of $10 \mathrm{~cm}$ from the base plate. The average heat loss through the side-walls was found to be $25.9 \%$. Schneebeli and Sokratov (2004) also observed heat losses through vertical walls as high as $22 \%$, for a smaller sample. Table 1 shows the heat losses from the apparatus as obtained for a test sample. The temperature distribution was recorded laterally at a height of $10 \mathrm{~cm}$ along the length of the snow sample. A temperature gradient of $1.5^{\circ} \mathrm{C} \mathrm{m}^{-1}$ was found, which indicates that there was probably some heat flow in the horizontal direction. A robust low-temperatureapplication data acquisition system (Model DT-800, DataTaker, Australia) was used, which was interfaced with a heat-flux unit for logging of temperatures and heat fluxes.

\subsection{Experiments}

Sieved natural snow was used for all the experiments. Snow was collected from Patsio (3800 ma.s.l.) research station, transported by air to the cold laboratory in insulated boxes and stored at $-20^{\circ} \mathrm{C}$. This snow was composed of fine grains with an average diameter up to $150 \mu \mathrm{m}$. The heat-flux apparatus was filled with the snow to a height of $0.20 \mathrm{~m}$ by using a $1.0 \mathrm{~mm}$ sieve opening.

Four sets of experiments were conducted in the heat-flux apparatus to monitor the structural changes in the snow sample due to the effects of temperature and temperature gradient. The thermal conductivity of snow was estimated using steady-state methods (Equation (2)). These experiments were conducted for 4 weeks each, and snow micrographs of vertical and horizontal surface sections were obtained on a weekly basis. The base heater was switched off 1 day before the snow sample was cut for the surface section preparation and density measurement. A snow sample of $0.2 \mathrm{~m}$ along the length of the snow sample was cut for the analysis. In this way, a sample size of $0.30 \times 0.20 \times 0.20 \mathrm{~m}^{3}$ was available each time for the thermal conductivity and microstructure analysis. The gap created by cutting the snow sample was refilled with similar snow by sieving. Details of all the experiments are given in Table 2.

\subsection{Microtoming}

In a cold room at $-10^{\circ} \mathrm{C}$, a smaller snow sample $(3 \times 3 \times$ $3 \mathrm{~cm}^{3}$ ) was cut from the bottom portion of the snow sample for microtoming. Dimethyl phthalate, a liquid pore filler, was poured around the sample until the liquid completely filled the pore space. The dimethyl phthalate was allowed to freeze overnight before sectioning the snow sample. Surfacesection samples were made following the procedure of Perla (1982). Microtoming was done in an automated polycut machine (Leica, Germany). Micrographs of horizontal and vertical surface sections were taken from the bottom half of the snow sample. In this way, a total of ten micrographs were taken for each sample. The micrographs were taken along with the measurement scale for image calibration so that details of each sample could be compared. These images were essentially greyscale and could easily be made into a binary for image processing.

\subsection{Image processing}

The digital image in Tagged Image File Format (TIFF) was loaded into the Image-Pro Plus (IPP) 4.0 software. Image information was adjusted using a greyscale threshold and then converted into a binary format. This is a crucial task for any user, as threshold limits cannot be defined precisely. Thresholding will always add some undesired portion or

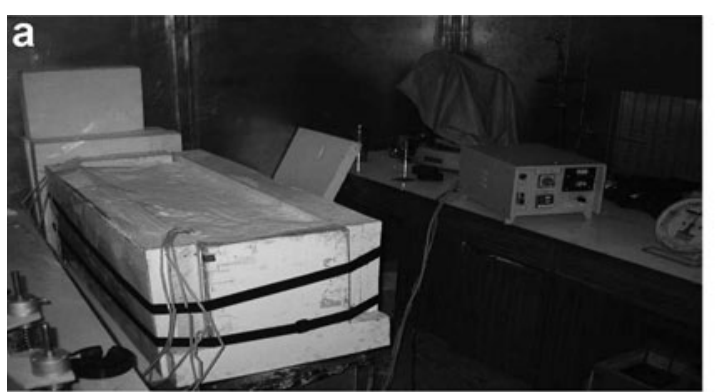

b

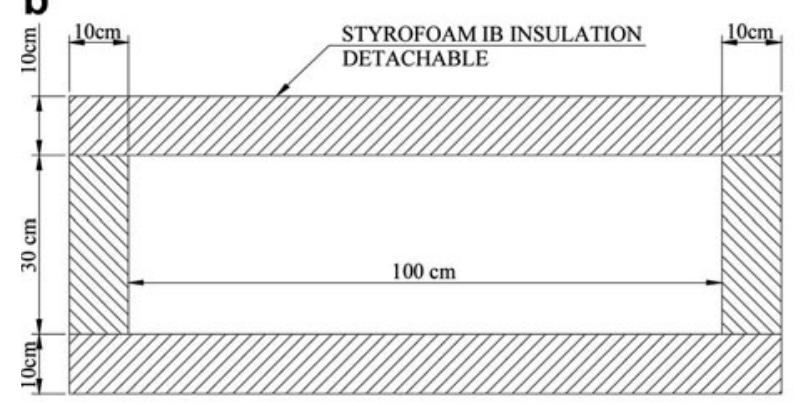

TOP VIEW

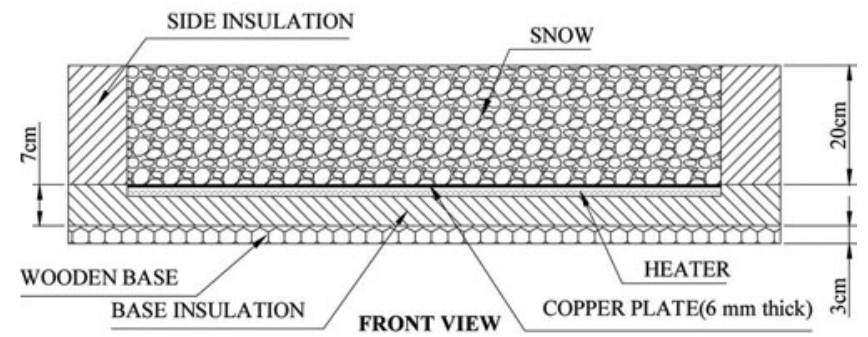

Fig. 1. (a) Photograph of heat-flux apparatus filled with snow. (b) Schematic of the experimental set-up (top and front views).

remove some important features, especially the connecting points on a micrograph. Utmost care was taken to manually adjust the connection between the grains. Since IPP software can edit the images, almost all micrographs were examined and modified before applying stereological analysis methods (Underwood, 1970). The image was finally saved in PICT format as input to a custom stereological analysis program (Edens, 1997). With the help of this program we determined the sample microstructural parameters.

Once the image is sufficiently processed, Edens' program (Edens, 1997) can calculate sample geometrical statistics from the digital images. This program calculates the mean intercept length (ice and pore), three-dimensional (3-D) grain and bond radius, area fraction of ice and specific surface area from a PICT image file. The software program assumes that the solid inclusion is spherical. The definition of grain bond given by Kry (1975) has been used in the current work. According to this, accepted definition for the bond to exist, a minimum constriction ratio of 0.7 must exist between connected segments of ice in a surface section plane. This means the maximum bond radius can reach up to $30 \%$ of the grain radius. Later, Edens (1997) found that a higher constriction ratio (i.e. bond radius $<30 \%$ of grain radius) works better for fine-grained round snow. In the current work, the microstructural parameters have been obtained for a fixed constriction ratio of 0.8 for each surface section. The area fraction and specific surface area were estimated prior to the bond segmentation of the image. 

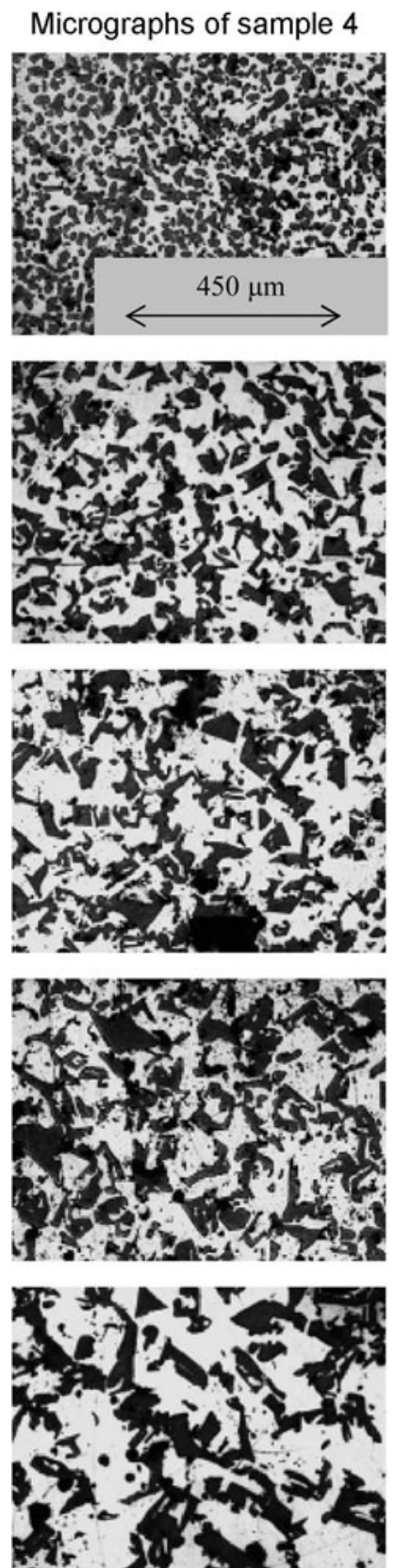

a Initial microstructure

b After 7 days

C After 14 days

d After 21 days
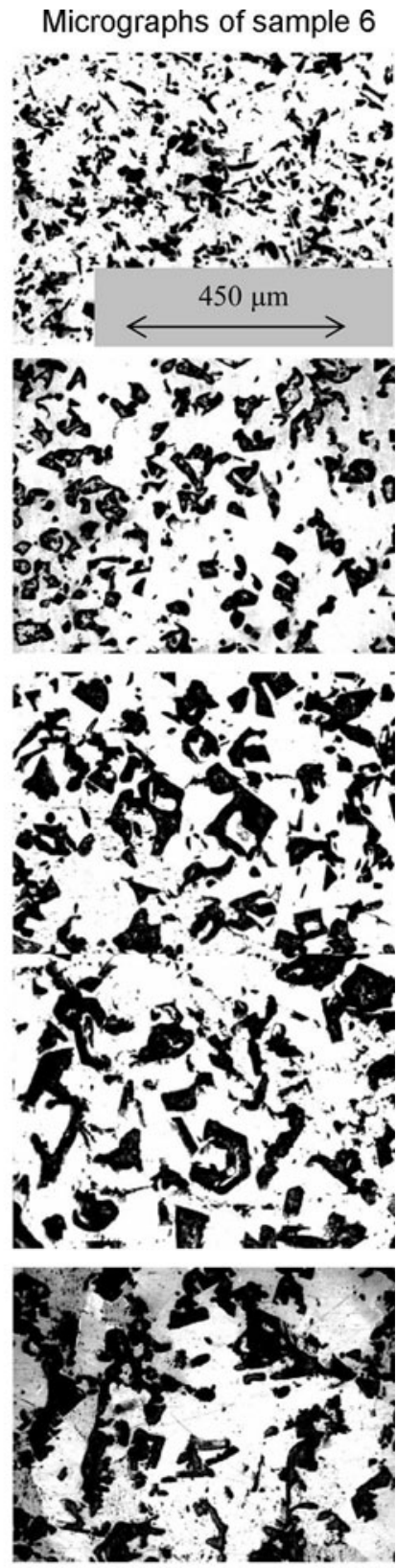

Fig. 2. A portion of horizontal surface section for snow samples 4 and 6 . A micrometer ruler is also shown for reference.

\subsection{Measurement of grain radius}

Two measures of grain size can be considered. One is the inscribed radius, which is the radius of the largest sphere that will fit inside an ice grain. If grains are rounded, the inscribed radius would be best for measuring grain size. For complicated grain shape, the volume-weighted volume was found to be the best measure of mean grain size (Edens, 1997). In the present work, the first method is preferred since our experimental snow did not grow very coarse in the beginning but only after the second and third week.

\section{RESULTS}

\subsection{Temporal changes in grain and bond radii (R_g and R_b)}

Quantitative microstructural parameters were obtained for all four snow samples. Figure $2 \mathrm{a}-\mathrm{e}$ show images of horizontal sections as a function of time for sample 4 (medium-density snow) and sample 6 (low-density snow) taken at the bottom of the sample. Over 40 surface sections were made ready for analysis. Illustrated in Figure 2 are subareas from these greyscale images. Our analysis is based on these micrographs. The structure of sample 6 was found to be coarse as compared to sample 4 after 14 days as shown in Figure 2. Figure 3 shows the grain radius, bond radius, grain and pore intercept length for sample 4 estimated for a horizontal section from the bottom portion. All these parameters show an increase in size with time, consistent with what is expected during temperature gradient metamorphism. Error bars in Figure 3 show the maximum error in the measurement of these parameters. Figure 4 shows specific surface area and area fraction of ice for sample 4. The specific surface area decreased rapidly in the beginning and then at a slower rate as metamorphism progressed. The area fraction of ice did not change much and no definite 


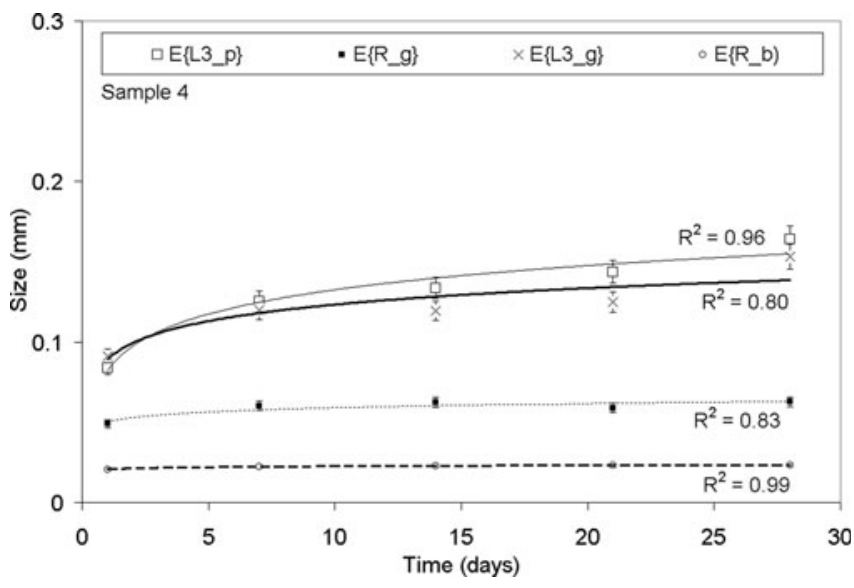

Fig. 3. The grain and pore intercept length, grain and bond radius as a function of time obtained for sample 4 from horizontal section. $E\left\{L 3 \_p\right\}$ is average pore intercept length, $E\left\{R_{-} g\right\}$ is average grain radius, $E\left\{L 3 \_g\right\}$ is average grain intercept length and $E\left\{R \_b\right\}$ is average bond radius. Standard mean error bars and regression coefficient of the trend are also shown.

trend was established. Grain intercept lengths and grain radii show rapid growth for sample 6 as compared to other samples as shown in Figure 5. Error bars in Figure 5 show the maximum error in the measurement of these parameters. The trends shown in Figures 3 and 5 have significant values of regression coefficients. Figure 6 shows specific surface area and area fraction of ice for sample 6, with a rapid decrease in specific surface area but little change in the area fraction of ice.

The evolution of various microstructural parameters for samples 3-6 is shown in Tables 3-6. The increasing magnitude of grain radius, bond radius, grain and pore intercept length for all the samples is shown in Table 7. In Figures 3 and 5, mean grain and bond radius is shown as a function of time. The trends of bond growth are similar to those observed for grain growth. The grain radius, bond radius, grain intercept length and pore intercept length evolved simultaneously, but at different rates as shown in Figure 3 for sample 4. Sample 6 shows the highest growth rate among all the snow samples, while sample 3 shows the lowest

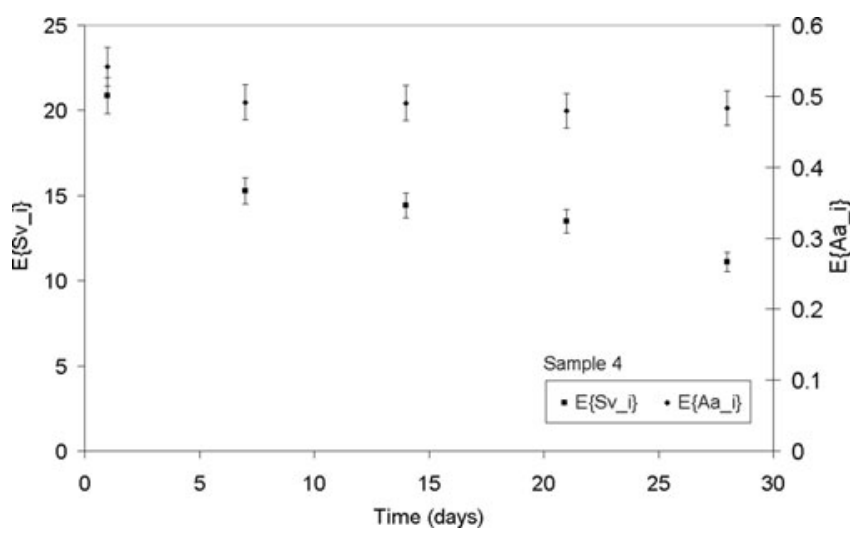

Fig. 4. The specific surface area and ice fraction for sample 4 as a function of time. These parameters show decreasing value with time. $E\left\{S v_{-} i\right\}$ is average specific surface area, and $E\left\{A a \_i\right\}$ is average ice fraction. Standard mean error bars are shown.

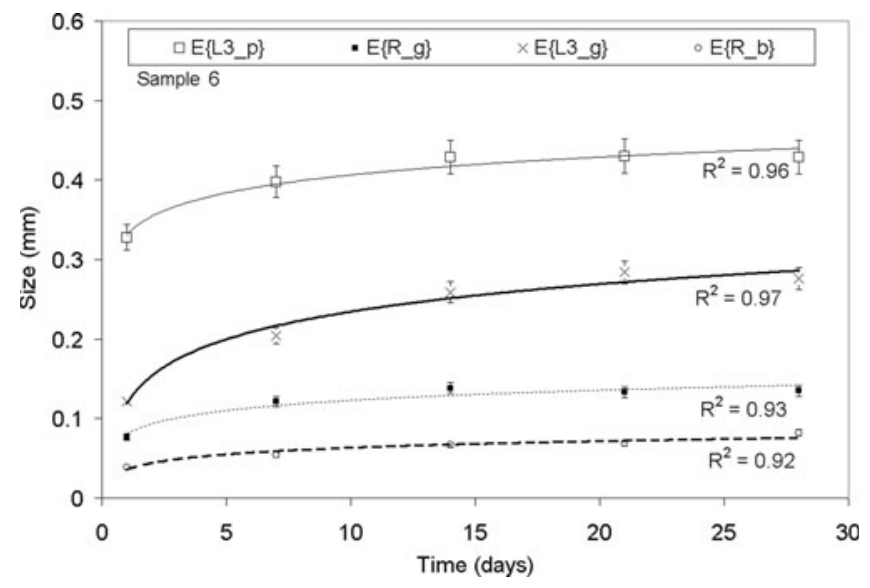

Fig. 5. The grain and pore intercept length, grain and bond radius as a function of time obtained for sample 6 from horizontal section. $E\left\{L 3 \_p\right\}$ is average pore intercept length, $E\left\{R \_g\right\}$ is average grain radius, $E\left\{L 3 \_g\right\}$ is average grain intercept length and $E\left\{R \_b\right\}$ is average bond radius. Standard mean error bars and regression coefficient of the trend are also shown.

growth rate as seen from Table 7 . Tables 3-6 also show the evolution of specific surface area and area fraction of ice with time.

\subsection{Temporal change in grain and pore intercept length (L3_g and L3_p)}

The ice area fraction and specific surface area are related to the mean pore intercept length, which is the inverse of the specific surface area (see Figs 3-6). The most important observation is that there is a general increase in traverse length across the pore space as metamorphism progresses (Fig. 2). Since it is unlikely that significant mass loss occurred, an increase in L3_p might be due to rearrangement of the ice into a more efficient configuration.

The expected values of mean L3_g, given in Tables 3-6, show trends very similar to those in Figures 3 and 5 with time. Mean grain and pore intercept lengths also show trends similar to those of grain and bond radius (Figs 3 and 5). As seen in Figures 3 and 5, L3_g increases almost twice as much in sample 6 as compared to sample 4 .

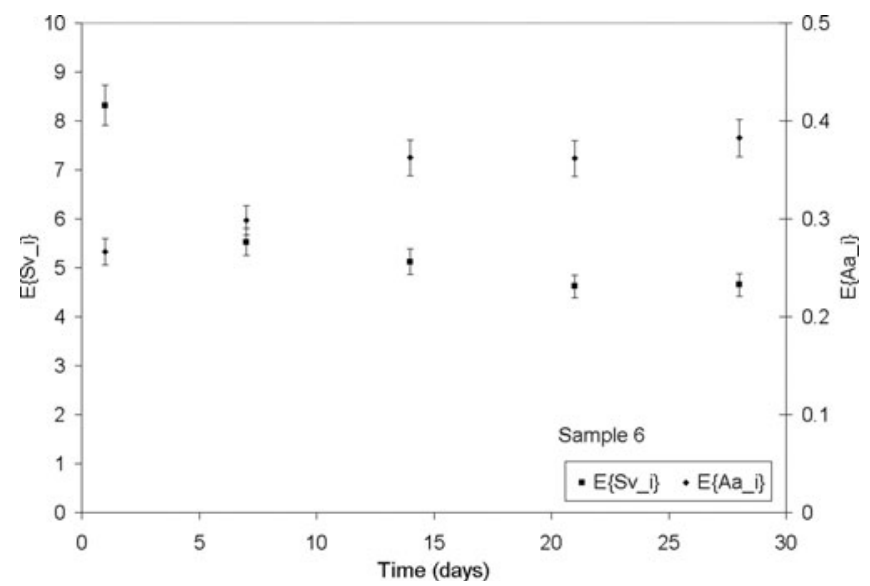

Fig. 6. Specific surface area and ice fraction for sample 6. These parameters show decreasing value with time. $E\left\{S v_{-} i\right\}$ is average specific surface area, and $\mathrm{E}\left\{\mathrm{Aa} \_\mathrm{i}\right\}$ is average ice fraction. Standard mean error bars are shown. 
Table 3. Various microstructural parameters obtained according to Edens (1997) for a horizontal surface section of snow micrographs taken at the bottom of the sample. The sample was subjected to a temperature gradient of $46^{\circ} \mathrm{C} \mathrm{m}^{-1}$ for 28 days. $E\left\{L 3 \_p\right\}$ is the average pore intercept length, $E\left\{R_{-} g\right\}$ is average grain radius, $E\left\{L 3 \_g\right\}$ is average grain intercept length and $E\left\{R \_b\right\}$ is average bond radius. $\mathrm{E}\left\{\mathrm{Sv}_{-} \mathrm{i}\right\}$ is the average specific surface area and $\mathrm{E}\left\{\mathrm{Aa} \mathrm{a}_{-} \mathrm{i}\right\}$ is average ice fraction

\begin{tabular}{|c|c|c|c|c|}
\hline \multirow[b]{2}{*}{ Parameter } & \multicolumn{4}{|c|}{ Time dependence of microstructural parameters for sample 3} \\
\hline & $\begin{array}{l}\text { After } \\
7 \text { days }\end{array}$ & $\begin{array}{l}\text { After } \\
14 \text { days }\end{array}$ & $\begin{array}{c}\text { After } \\
21 \text { days }\end{array}$ & $\begin{array}{c}\text { After } \\
28 \text { days }\end{array}$ \\
\hline \multicolumn{5}{|c|}{ Horizontal section } \\
\hline$E\left\{L 3 \_p\right\}$ & 0.149 & 0.209 & 0.179 & 0.179 \\
\hline$E\left\{R \_g\right\}$ & 0.049 & 0.057 & 0.055 & 0.052 \\
\hline $\mathrm{E}\{\mathrm{L} 3$ g $\mathrm{g}\}$ & 0.111 & 0.143 & 0.123 & 0.129 \\
\hline E\{R_b $\}$ & 0.019 & 0.020 & 0.021 & 0.022 \\
\hline$E\left\{A a \_i\right\}$ & 0.431 & 0.401 & 0.421 & 0.424 \\
\hline$E\left\{S v_{-} i\right\}$ & 14.185 & 9.979 & 11.924 & 11.969 \\
\hline
\end{tabular}

\subsection{Temporal changes in specific surface area and ice fraction (Sv_i and $\mathbf{A a} \_\mathrm{i}$ )}

Initially, each binary image of samples 3-6 was analyzed to obtain ice area fraction as well as the specific ice surface area. The changes in Sv_i and Aa_i with time are shown in Figures 4 and 6 . Notice that within the first week the relative surface area decreased by roughly 35\% for samples 4 and 6 (Figs 4 and 6). Samples 3 and 5 also show similar reductions during the first week of metamorphism (Tables 3 and 5). It is interesting that, through the first week, specific surface area reduces at almost the same rate for each temperature range. This suggests that curvature effects are the dominant driving mechanism during the initial period of metamorphism (Colbeck, 1983; Brown and others, 1994). It should be noted that the values of microstructural parameters are not consistent after a 14 day period (Tables 3 and 5).

Table 4. Various microstructural parameters obtained according to Edens (1997) for horizontal and vertical surface sections of snow micrographs taken at the bottom of the sample. The sample was subjected to a temperature gradient of $28^{\circ} \mathrm{C} \mathrm{m}^{-1}$ for 28 days. Notations are given in Table 3 caption

Time dependence of microstructural parameters for sample 4

$\begin{array}{cccccc}\text { Parameter } & \text { At } & \text { After } & \text { After } & \text { After } & \text { After } \\ & \text { the start } & 7 \text { days } & \text { 14 days } & 21 \text { days } & 28 \text { days }\end{array}$

\begin{tabular}{|c|c|c|c|c|c|}
\hline \multicolumn{6}{|c|}{ Horizontal section } \\
\hline $\mathrm{E}\left\{\mathrm{L} 3 \_p\right\}$ & 0.084 & 0.125 & 0.134 & 0.144 & 0.164 \\
\hline$E\left\{R \_g\right\}$ & 0.049 & 0.060 & 0.062 & 0.059 & 0.063 \\
\hline$E\left\{L 3 \_g\right\}$ & 0.091 & 0.120 & 0.119 & 0.125 & 0.153 \\
\hline$E\left\{R \_b\right\}$ & 0.021 & 0.023 & 0.023 & 0.023 & 0.023 \\
\hline$E\left\{A a \_i\right\}$ & 0.542 & 0.491 & 0.490 & 0.479 & 0.484 \\
\hline$E\left\{S v_{-} i\right\}$ & 20.860 & 15.288 & 14.414 & 13.497 & 11.107 \\
\hline \multicolumn{6}{|c|}{ Vertical section } \\
\hline $\mathrm{E}\left\{\mathrm{L} 3 \_p\right\}$ & 0.084 & 0.122 & 0.121 & 0.129 & 0.159 \\
\hline$E\left\{R \_g\right\}$ & 0.049 & 0.055 & 0.052 & 0.053 & 0.059 \\
\hline$E\left\{L 3 \_g\right\}$ & 0.091 & 0.120 & 0.130 & 0.143 & 0.155 \\
\hline$E\left\{R \_b\right\}$ & 0.021 & 0.021 & 0.021 & 0.021 & 0.021 \\
\hline$E\left\{A a \_i\right\}$ & 0.542 & 0.524 & 0.536 & 0.558 & 0.528 \\
\hline$E\left\{S v_{-} i\right\}$ & 20.860 & 14.881 & 14.625 & 13.187 & 11.102 \\
\hline
\end{tabular}

Table 5. Various microstructural parameters obtained according to Edens (1997) for horizontal and vertical surface sections of snow micrographs taken at the bottom of the sample. The sample was subjected to a temperature gradient of $45^{\circ} \mathrm{C} \mathrm{m}^{-1}$ for 28 days. Notations are given in Table 3 caption

Time dependence of microstructural parameters for sample 5

\begin{tabular}{|c|c|c|c|c|c|}
\hline Parameters & $\begin{array}{c}\text { At } \\
\text { the start }\end{array}$ & $\begin{array}{l}\text { After } \\
7 \text { days }\end{array}$ & $\begin{array}{l}\text { After } \\
14 \text { days }\end{array}$ & $\begin{array}{c}\text { After } \\
21 \text { days }\end{array}$ & $\begin{array}{c}\text { After } \\
28 \text { days }\end{array}$ \\
\hline \multicolumn{6}{|c|}{ Horizontal section } \\
\hline$E\left\{L 3 \_p\right\}$ & 0.087 & 0.147 & 0.115 & 0.172 & 0.168 \\
\hline$E\left\{R \_g\right\}$ & 0.053 & 0.053 & 0.056 & 0.072 & 0.080 \\
\hline$E\left\{L 3 \_g\right\}$ & 0.100 & 0.123 & 0.120 & 0.162 & 0.149 \\
\hline$E\left\{R \_b\right\}$ & 0.020 & 0.020 & 0.023 & 0.026 & 0.025 \\
\hline$E\left\{A a \_i\right\}$ & 0.559 & 0.450 & 0.540 & 0.478 & 0.484 \\
\hline$E\left\{S_{-} i\right\}$ & 19.130 & 13.494 & 15.277 & 10.311 & 11.377 \\
\hline \multicolumn{6}{|c|}{ Vertical section } \\
\hline E\{L3_p $\}$ & 0.087 & 0.111 & 0.105 & 0.210 & 0.154 \\
\hline$E\left\{R \_g\right\}$ & 0.053 & 0.054 & 0.057 & 0.072 & 0.061 \\
\hline$E\left\{L 3 \_g\right\}$ & 0.100 & 0.109 & 0.126 & 0.165 & 0.138 \\
\hline$E\left\{R \_b\right\}$ & 0.020 & 0.022 & 0.022 & 0.020 & 0.025 \\
\hline$E\left\{A_{a} \_i\right\}$ & 0.559 & 0.496 & 0.566 & 0.441 & 0.487 \\
\hline$E\left\{S v_{\_} i\right\}$ & 19.130 & 16.547 & 15.329 & 9.261 & 11.350 \\
\hline
\end{tabular}

\subsection{Effective thermal conductivity (ETC)}

The change in ETC with time for samples 4 and 6, shown in Figure 7, generally increases. ETC for both samples started from a similar value, but after 28 days sample 6 shows a higher ETC than sample 4. In both samples, ETC started increasing immediately when a temperature gradient was applied. The increase in ETC values was found to be nearly $33 \%$ for sample 4 , and $80 \%$ for sample 6 , at a constant snow density. There are no data for the $7 \mathrm{th}, 14 \mathrm{th}$ and 21 st days due to the time required for microstructure measurements and because the heat-flux apparatus was switched off for 2 days. The ETC of both samples (Fig. 7) show similar trends in grain radius, bond radius, grain intercept length and pore intercept length as a function of time (Figs 3 and 5). These parameters show strong positive correlation with ETC. A positive correlation of 0.84 was found between ETC and L3_g for sample 4 and 0.89 for sample 6. ETC and L3_p also correlated positively, with a correlation coefficient of 0.85 for sample 4 and 0.81 for sample 6 . A negative correlation was found between ETC and Sv_i, with a value of 0.82 for sample 4 and 0.80 for sample 6. ETC and Aa_i also correlated negatively, with a correlation coefficient of 0.64 for sample 4 and 0.95 for sample 6 . Weak correlation was found between ETC and R_g and between ETC and R_b for sample 4, with correlation coefficients of 0.58 and 0.52 respectively. However, for sample 6, good correlation was found between ETC and R_g and between ETC and R_b, with values 0.76 and 0.96 respectively.

\section{DISCUSSION}

Two-dimensional (2-D) snow structure observed using the surface section method is consistent with the manually observed grain size and grain shape. Stereology used to describe various microstructural parameters assumes that snow is a collection of solid spherical grains (Edens, 1997). Although bond radius as determined from stereology is 
Table 6. Various microstructural parameters obtained according to Edens (1997) for a horizontal surface section of snow micrographs taken at the bottom of the sample. The sample was subjected to a temperature gradient of $28^{\circ} \mathrm{C} \mathrm{m}^{-1}$ for 28 days. Notations are given in Table 3 caption

Time dependence of microstructural parameters for sample 6

\begin{tabular}{lccccc} 
Parameter & $\begin{array}{c}\text { At } \\
\text { the start }\end{array}$ & $\begin{array}{c}\text { After } \\
7 \text { days }\end{array}$ & $\begin{array}{c}\text { After } \\
\text { 14 days }\end{array}$ & $\begin{array}{c}\text { After } \\
\text { 21 days }\end{array}$ & $\begin{array}{c}\text { After } \\
\text { 28 days }\end{array}$ \\
\hline Horizontal & section & & & & \\
E\{L3_p\} & 0.328 & 0.399 & 0.429 & 0.436 & 0.430 \\
E\{R_g\} & 0.077 & 0.121 & 0.138 & 0.134 & 0.136 \\
E\{L3_g\} & 0.122 & 0.204 & 0.259 & 0.284 & 0.277 \\
E\{R_b & 0.039 & 0.054 & 0.067 & 0.070 & 0.083 \\
E\{Aa_i $\}$ & 0.267 & 0.298 & 0.362 & 0.362 & 0.383 \\
E\{S_i $\}$ & 8.320 & 5.528 & 5.126 & 4.624 & 4.657 \\
\hline
\end{tabular}

sensitive to the constriction parameter, a constant constriction value of 0.8 was used as suggested by Edens (1997). The bond size as estimated by this method also uses the assumption of spherical particles. The inconsistency found in the values of microstructural parameters (Tables 3 and 5) after 14 days of the experiment could be due to the assumptions made in applying the stereology. One assumption is considering the snow grains as spherical particles, and another is fixing the constriction ratio as 0.8 . The third important parameter that may affect our result is the grain shape, which changes throughout the experiment, so a continuous departure in grain shape, from spherical particles to faceted, will modify the values.

The grain sizes as observed for all the samples are smaller than the previously observed grain size under temperature gradient (Giddings and LaChapelle, 1962; Satyawali, 1994; Baunach and others, 2001). The main reason for the smaller grain size is the fact that our observations are made from 2-D plane rather than from direct observation of disaggregated grains. The grain size as a function of time appears to be directly related to the specific surface area, which decreases with time once a temperature gradient is applied to the snow.

The increase in ETC values is found to be nearly $33 \%$ for sample 4 , and $80 \%$ for sample 6 , at a constant snow density. This shows that density is not the only contributing factor to ETC, but it is actually the snow microstructure that is more important and also relates to snow density (Sturm and others,

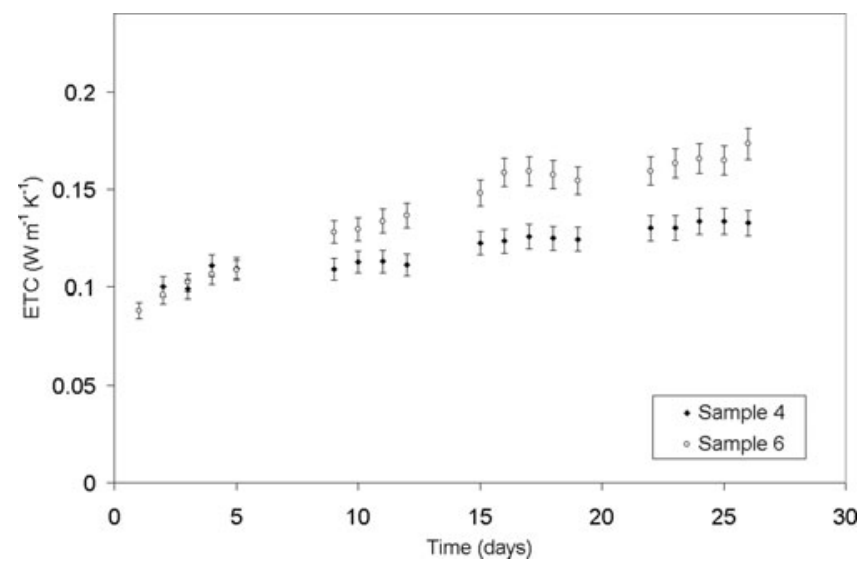

Fig. 7. Evolution of ETC for samples 4 and 6. ETC of both samples start from similar values, but the low-density snow (sample 6) reached a higher value of ETC after 28 days for similar temperature gradient applied to both samples. There are no data for the 7 th, 14 th and 21 st days, due to test apparatus being switched off for 2 days.

$1997,2002)$. The maximum increase in snow density after 28 days, as observed for sample 6 , is $11 \%$ (Table $1 \mathrm{~b}$ ), which is not sufficient to explain the doubling in the magnitude of ETC. Grain bond radius as a function of time is well correlated with the change in ETC and provides a good explanation for the current observations of increasing ETC, especially for sample 6 (Figs 5 and 7). The general observation that the evolution of snow structure due to an imposed temperature gradient weakens the snow strength cannot be explained from the present work.

The ETC for snow is well correlated with the increase in grain and bond radius (Figs 3-7), and a very good correlation is found between ETC and microstructural parameters. ETC never decreases at the start of an experiment, even for lowdensity snow as was observed by Schneebeli and Sokratov (2004). The change in ETC cannot be attributed solely to a change in snow density, which changes at much slower rates.

\section{CONCLUSION}

Four experiments on temperature gradient metamorphism were conducted in a cold laboratory in order to investigate changes in snow microstructure and ETC with time. ETC and quantitative microscopy measurements were made on sieved snow samples prepared in the cold laboratory. Changes in

Table 7. Grain and bond radius as a function of time and mass growth rates for various snow samples. Horizontal sections show higher mass growth rates as compared to vertical sections for samples 4 and 5

\begin{tabular}{|c|c|c|c|c|c|}
\hline Parameter & Section plane & Sample 3 & Sample 4 & Sample 5 & Sample 6 \\
\hline \multirow[t]{2}{*}{ Growth in pore intercept length (L3_p) $\left(\mu \mathrm{md}^{-1}\right)$} & Horizontal & 1.396 & 2.859 & 2.886 & 3.384 \\
\hline & Vertical & - & 2.691 & 2.389 & - \\
\hline \multirow[t]{2}{*}{ Growth in grain intercept length (L3_g) $\left(\mu \mathrm{m} \mathrm{d}^{-1}\right)$} & Horizontal & 0.829 & 2.216 & 1.742 & 4.565 \\
\hline & Vertical & - & 2.290 & 1.354 & - \\
\hline Growth in grain radius $\left(\mathrm{R} \_g\right)\left(\mu \mathrm{m} \mathrm{d}^{-1}\right)$ & Horizontal & 0.164 & 0.488 & 0.986 & 1.358 \\
\hline \multirow[t]{2}{*}{ Growth in bond radius (R_b), $\left(\mu \mathrm{m} \mathrm{d}^{-1}\right)$} & Horizontal & 0.114 & 0.095 & 0.170 & 0.337 \\
\hline & Vertical & - & 0.016 & 0.176 & - \\
\hline \multirow[t]{2}{*}{ Mass growth rate $\left(\mathrm{g} \mathrm{d}^{-1}\right)$} & Horizontal & $4.853 \times 10^{-9}$ & $1.763 \times 10^{-8}$ & $5.082 \times 10^{-8}$ & $1.456 \times 10^{-7}$ \\
\hline & Vertical & - & $1.158 \times 10^{-8}$ & $1.128 \times 10^{-8}$ & - \\
\hline
\end{tabular}


ETC values were found to be dependent on changes in microstructural parameters with time. Microstructural measurements, even if all objectivity and consistency needs are met, are dependent upon the quality of surface sections. Although considerable efforts were made in this area, obtaining consistent ice-pore contrast still remains a problem. In a recent study, this problem was removed (Schneebeli and Sokratov, 2004), but at a heavy expense.

Both microstructure and ETC vary slowly with time. In all tests, ETC increased with time even if some bond disintegration occurred during temperature gradient metamorphism. This is attributed to the fact that vertical bonds/ connections might have grown at a faster rate than bond disaggregation, resulting in higher heat conduction.

The destructive techniques used for the microstructure measurements in this study may introduce some error due to the small amount of variability within a sample, but our results are sufficient to establish a correlation between ETC and microstructure. The quantitative formulations have not been established in this work, as the experimentation done is based on selected density, temperature range and known history of snow. Nonetheless, the present experimental work is able to demonstrate the effect of microstructural parameters on effective thermal conductivity.

\section{ACKNOWLEDGEMENTS}

We thank R.N. Sarwade, Director SASE, for allowing this work to be published. We also thank M. Sturm, J. Johnson and M. Schneebeli for critical comments and useful discussions.

\section{REFERENCES}

Adams, E.E. and A. Sato. 1993. Model for effective thermal conductivity of a dry snow cover composed of uniform ice spheres. Ann. Glaciol., 18, 300-304.

Akitaya, E. 1974. Studies on depth hoar. Contrib. Inst. Low Temp. Sci., Ser. A, 26, 1-67.

Arons, E.M. and S.C. Colbeck. 1995. Geometry of heat and mass transfer in dry snow: a review of theory and experiment. Rev. Geophys., 33(4), 463-493.

Arons, E.M. and S.C. Colbeck. 1998. Effective medium approximation for the conductivity of sensible heat in dry snow. Int. J. Heat Mass Transfer, 41(17), 2653-2666.

Arons, E.M., S.C. Colbeck, W.R. McGilvary and V.F. Petrenko. 1994. Effective medium approximation for snow thermal conductivity. In Agrawal, K.C., ed. Proceedings of the International Symposium on Snow and Related Manifestations 'SNOWSYMP 94', 26-28 September 1994, Manali. Manali, Snow and Avalanche Study Establishment, 141-145.

Bartelt, P. and M. Lehning. 2002. A physical SNOWPACK model for the Swiss avalanche warning. Part I: numerical model. Cold Reg. Sci. Technol., 35(3), 123-145

Baunach, T., C. Fierz, P.K. Satyawali and M. Schneebeli. 2001. A model for kinetic grain growth. Ann. Glaciol., 32, 1-6.

Brown, R.L., M.Q. Edens and A. Sato. 1994. Metamorphism of finegrained snow due to surface curvature differences. Ann. Glaciol., 19, 69-76.
Brown, R.L., M.Q. Edens and M. Barber. 1999. Mixture theory of mass transfer based upon microstructure. Def. Sci. J., 49(5), 393-409.

Brun, E., P. David, M. Sudul and G. Brunot. 1992. A numerical model to simulate snow-cover stratigraphy for operational avalanche forecasting. J. Glaciol., 38(128), 13-22.

Colbeck, S.C. 1983. Ice crystal morphology and growth rates at low supersaturations and high temperatures. J. Appl. Phys., 54(5), $2677-2682$

Edens, M.Q. 1997. An experimental investigation of metamorphism induced microstructure evolution in a 'model' cohesive snow. (PhD thesis, Montana State University.)

Giddings, J.C. and E. LaChapelle. 1962. The formation rate of depth hoar. J. Geophys. Res., 67(6), 2377-2383.

Kaempfer, T.U., M. Schneebeli and S.A. Sokratov. 2005. A microstructural approach to model heat transfer in snow. Geophys. Res. Lett., 32(21), L21503. (10.1029/2005GL023873.)

Kry, P.R. 1975. Quantitative stereological analysis of grain bonds in snow. J. Glaciol., 14(72), 467-477.

Lehning, M., P. Bartelt, B. Brown, C. Fierz and P. Satyawali. 2002. A physical SNOWPACK model for the Swiss avalanche warning. Part II: snow microstructure. Cold Reg. Sci. Technol., 35(3), 147-167.

Perla, R. 1982. Preparation of section planes in snow specimens. J. Glaciol., 28(98), 199-204.

Sato, A. and E.E. Adams. 1995. Model for effective thermal conductivity of a dry snow cover composed of uniform ice spheres. Seppyo, J. Jpn. Soc. Snow Ice, 57(2), 133-140.

Satyawali, P.K. 1994. Grain growth under temperature gradient: a simple approach. In Agrawal, K.C., ed. Proceedings of the International Symposium on Snow and Related Manifestations, 'SNOWSYMP 94', 26-28 September 1994, Manali. Manali, Snow and Avalanche Study Establishment, 52-62.

Schneebeli, M. and S.A. Sokratov. 2004. Tomography of temperature gradient metamorphism of snow and associated changes in heat conductivity. Hydrol. Process., 18(18), 3655-3665.

Sturm, M. 1991. The role of thermal convection in heat and mass transport in the subarctic snow cover. CRREL Rep. 91-19.

Sturm, M. and J.B. Johnson. 1992. Thermal conductivity measurements of depth hoar. J. Geophys. Res., 97(B2), $2129-2139$.

Sturm, M., J. Holmgren, M. König and K. Morris. 1997. The thermal conductivity of seasonal snow. J. Glaciol., 43(143), 26-41.

Sturm, M., D.K. Perovich and J. Holmgren. 2002. Thermal conductivity and heat transfer through the snow on the ice of the Beaufort Sea. J. Geophys. Res., 107(C10), 8043. (10.1029/ 2000JC000409.)

Underwood, E.E. 1970. Quantitative stereology. Reading, MA, Addison-Wesley Publishing.

Wakeham, W.A. and M.J. Assael. 1999. Thermal conductivity measurement. In Webster, J.G., ed. The measurement, instrumentation and sensors handbook. Boca Raton, FL, CRC Press.

Yen, Y.C. 1962. Effective thermal conductivity of ventilated snow. J. Geophys. Res., 67(3), 1091-1098.

Yen, Y.C. 1965. Effective thermal conductivity and water vapor diffusivity of naturally compacted snow. J. Geophys. Res., 70(8), 1821-1825.

Yen, Y.C. 1981. Review of thermal properties of snow, ice and sea ice. CRREL Rep. 81-10.

Yosida, Z. and 6 others. 1955. Physical studies on deposited snow. I. Thermal properties. Contrib. Inst. Low Temp. Sci., Ser. A, 7, $19-74$. 